\title{
A Psychodynamic Psychotherapy Approach to the Emotional Problems of Exceptionally and Profoundly Gifted Adolescents and Adults: A Psychiatrist's Experience
}

\author{
Jerald Grobman \\ Private Practice
}

An eclectic form of psychodynamic psychotherapy is presented to address the emotional problems of exceptionally and profoundly gifted adolescents and adults. The approach includes cognitive/behavioral techniques as well as psychologically informed mentoring, coaching, and advising. Once a psychodynamic formulation was established, it was used to guide all subsequent therapeutic interventions. Three phases of psychotherapy can be recognized. In the first phase, patients addressed their guilt about being exceptionally endowed. They elaborated and organized a personal vision for their giftedness and found an appropriate venue for its expression. In the second phase, patients modulated their need for complete autonomy so they could collaborate more effectively with the therapist and others. In the third phase, patients were able to integrate their extracognitive abilities with their superior intellect. They learned more mature methods of conflict resolution and were able to employ all aspects of their gifted endowment more effectively.

\section{Background}

This clinical report is the sequel to a previous one (Grobman, 2006) in which I described a group of exceptionally gifted adolescents and young adults who had become underachievers because of their inability to resolve certain conflicts that accompanied each stage of their development. In this report, I will describe and discuss the issues and the therapeutic tasks that arose in each stage of their psychotherapy. My hope is to add to clinical observations made in individual psychotherapy case reports (Colarusso, 1980; Dahlberg, 1992; Kelly,

Jerald Grobman is a board certified psychiatrist who specializes in the psychodynamic and cognitive/ behavioral psychotherapy of gifted adolescents and adults.

Journal for the Education of the Gifted. Vol. 33, No. 1, 2009, pp. 106-125. Copyright (C2009 Prufrock Press Inc., http://www.prufrock.com 
1970; Oremland, 1975); to add to the general observations made by those who have counseled (Colangelo \& Assouline, 2000; Kerr, 2007; Mendaglio \& Peterson, 2007; Rocamora, 1992; Silverman, 2000) and treated gifted adolescents and adults with psychotherapy (Jacobsen, 1999; Lovecky, 1990); to add clinical guidelines for the evaluation and treatment of interpersonal and intrapsychic conflicts and anxieties that may be specific to exceptional and profoundly gifted individuals; and to add to our understanding of the psychology of exceptionally and profoundly gifted individuals.

All of my patients were middle class and ranged in age from 15 to 35. They came from stable, functional families and had parents, peers, and schools who recognized and supported their giftedness. These patients were exceptionally or profoundly gifted in music, art, theatre, literature, or science. Some were gifted in several of these areas. They all had an intense drive to explore and master their environment, special physical sensitivities, distinct aesthetic sensibilities, and a strong need to function autonomously. Despite their different cultural and ethnic backgrounds, different personalities, and unique ways of expressing their giftedness, they all came to psychotherapy in crisis; and their psychotherapy unfolded in predictable stages. Similar issues and therapeutic challenges arose in each phase of their psychotherapy.

My theoretical orientation has been and remains a psychiatric and psychodynamic one. But my therapeutic approach has become eclectic. More than 27 years of clinical work with gifted adolescents and adults has taught me some important lessons about the special conflicts and anxieties of exceptionally and profoundly gifted individuals and how to treat them in psychotherapy.

\section{Special Conflicts and Anxieties}

For these patients, conflicts and anxieties about their inner experience of giftedness were usually more important in causing underachievement and self-destructive behavior than conflicts and anxieties about parents, school or work, and peers. In normally endowed individuals, vulnerabilities and strengths often seem like separate parts of their personality. Weakness can sometimes be avoided because strengths compensate for them. In my patients, however, different parts of their remarkable endowment could simultaneously feel like strengths and 
weaknesses. It was this phenomenon that was at the heart of many of the conflicts within their inner experience of giftedness.

\section{Methods of Conflict Resolution}

Because of their extreme physical and aesthetic sensitivities, each of my patients experienced emotion and emotional conflict in very intense ways. Although their intellect was highly developed, they used surprisingly primitive methods of denial and avoidance to manage their conflicts and anxieties. These attempts to completely eliminate conflict and anxiety invariably led to underachievement, self-destructive behavior, and severe psychological symptoms.

\section{The Nature of Psychotherapy}

Psychotherapy with exceptionally and profoundly gifted individuals needs to be a vibrant endeavor. A traditional approach-the therapist as a thoughtful, but somewhat removed observer-does not work. For me, a lively, engaged, and interactive approach that also incorporates the ability to stand back, observe, understand, clarify, and interpret the content and process has proved more effective.

Although my approach with gifted patients is an eclectic one, this does not mean that I am continuously shifting my theoretical orientation or technique. It does mean I often use the techniques of coaching, mentoring, psychoeducation, case management, and cognitive/behavioral therapy to enhance my interventions. As long as I can maintain a clear understanding of how my patients' normal developmental conflicts and anxieties intersect with conflicts and anxieties about their giftedness, the psychotherapy will have an anchored and consistent focus.

A firm grip on each patient's psychodynamic formulation also allows me to be flexible and adaptive. I can be prepared to see their psychological problems in fresh ways, appreciate how their gifted endowment interacts with other parts of their personality, and be ready to invent individual "on the spot" therapeutic approaches worthy of each individual's unique form of giftedness. 


\section{Therapeutic Tasks in Crisis Management}

Their powerful need for independence having prevented them from asking for help sooner, all of the gifted individuals referred to me were in crisis: their work, school life, relationships, and physical health were in disarray. Many had developed serious forms of depression and anxiety. Some felt they were headed for hospitalization.

Once they accepted their need for help, each patient was receptive to and grateful for a hands-on, take-charge approach. Frequent, flexible, and intense sessions, as well as direct and decisive interventions, were essential in the early stages of building a firm therapeutic alliance. At times, I needed to be available by telephone, at night or during weekends. Turbulent, chaotic, and disastrous as it sometimes was, a full-blown gifted crisis could be transformed into an opportunity for growth.

\section{An Accurate Diagnosis of Psychological Symptoms}

My earliest diagnostic task was to distinguish between the symptoms of a gifted person in crisis from one with a true psychiatric or personality disorder. Common misdiagnoses are depressive, bipolar, obsessive compulsive, generalized anxiety, panic, narcissistic and borderline personality disorders (American Psychiatric Association, 1994).

\section{The Use of Psychotropic Medication}

Once I understood each patient's symptom profile, I could, when necessary, prescribe appropriate medication. This helped them achieve rapid psychological control so that they could quickly return to work or school. Feeling more emotionally stable also helped my gifted patients take better care of their physical health and personal hygiene and improve their interpersonal relationships. Once a solid therapeutic alliance was established, medication frequently could be reduced and then eliminated. 
Stress Management

During the initial phase of crisis management, it was important for me to suggest techniques to help eliminate substance abuse and selfdestructive behavior. Providing guidelines for healthy nutrition, better sleep habits, and sensible work or study schedules were also important.

\section{Establishing a Therapeutic Alliance}

Building mutual rapport, clarifying mutually agreed-upon goals and creating a belief that psychotherapy will work can be difficult with any patient in crisis. However, once they feel more in control, most patients are ready to find out what happened to them and to figure out what to do about it. Gifted patients, too, may feel relieved and grateful once their symptoms abate. But for them, settling into psychotherapy may be more difficult.

As they gain more control, their need for independence may stimulate a desire to leave psychotherapy prematurely. Sadly, an impulsive departure from therapy almost always ensures the return of underachievement, self-destructive behavior, and psychological symptoms. Gifted patients and individuals may also leave psychotherapy too early because they feel that therapists simply do not "get" giftedness. Many therapists can be fascinated by a gifted individual's quirky intelligence and unusual accomplishments but may also believe that a gifted person's painful symptoms and personality traits are part of a standard psychiatric syndrome or disorder.

I agree with Kerr (2007) that addressing giftedness early in the counseling or psychotherapy process helps develop a therapeutic alliance. However, I have found this is best done indirectly. Some of my patients adamantly refused to be identified as gifted. Many accepted the "gifted" label reluctantly and only much later in the therapy. Inquiring in a casual but informed and empathic way about special abilities, unusual sensitivities, and particular conflicts and anxieties conveys an understanding of the inner experience of giftedness. Connecting with my patients in this way helped them understand that I had more to offer than symptom relief and paved the way for deeper therapeutic work. 


\section{The Psychodynamic Assessment Process}

My assessment process is a comprehensive one. It includes taking a history of gifted development - exceptional achievements as well as underachievements and failures - and a complete personal, social, educational, family, and medical history. The assessment process also involves a review of all previous therapies, testing results, and psychological work-ups. All parts of a gifted individual's present and past personal experience are separately explored in depth. Understanding how these experiences interact with each other helps establish a preliminary psychodynamic formulation. This formulation is a brief statement that describes how a patient's circumstances as well as unresolved developmental conflicts may be responsible for their symptoms, complaints, and problems.

In the case of a gifted individual, the formulation can be used as a psychological framework for understanding how normal and gifted growth have complemented or conflicted with one another. It establishes each patient's vulnerabilities and strengths, and it clarifies how unresolved feelings about early childhood experiences may have caused persistent conscious or unconscious conflicts that can influence current thinking, feeling, and behavior. In doing so, the formulation helps in understanding the patient's central dynamic conflicts (Perry, Cooper, \& Michels, 1987). In my patients, the majority of these conflicts were about the inner experience of giftedness, not about family, peers, or school and work.

The elements of a formulation become the building blocks for a comprehensive treatment plan. As the psychotherapy is set in motion, the formulation provides a consistent focus for the treatment, but it remains flexible-expanding and contracting as the patient and therapist get to know each other. Most importantly, the formulation does not simply reduce the meaning of a gifted person's life to a few psychological conflicts. Moreover, the formulation can be an important diagnostic tool when used to understand gifted/learning-disabled individuals and gifted polymaths with Attention Deficit/Hyperactivity Disorder (ADHD).

\section{Gifted/Learning-Disabled Individuals}

Distinguishing between a twice-exceptional individual—a gifted person with a true neurologically based learning disability - from 
a gifted person with a "pseudo learning disability" can be difficult. Some gifted children, especially those who are exceptionally or profoundly gifted, may believe that because of their quirky intelligence their peculiar style of learning is actually a disability rather than an asset. Others may impose restrictions on their ability to learn as a way of resolving internal or interpersonal conflicts about their extreme giftedness (Grobman, 2006). These self-imposed deficits may mimic a true neurologically based learning disability.

\section{The Gifted Polymath}

A careful assessment and formulation can distinguish a gifted polymath in crisis from a gifted person with ADHD. A true polymath-an individual exceptionally gifted in many different domains - can be highly accomplished in many areas simultaneously. Under normal circumstances, gifted polymaths are natural and successful multitaskers. Under extreme stress, their ability to concentrate may break down. The resultant loss of focus, distractibility, and eccentric behavior may mimic ADHD.

\section{Beginning Psychotherapy Proper}

As each patient's crisis receded and he or she gained more physical and psychological control, my approach became less directive and structured. Now we both could turn our attention to a more complete description of current circumstances and establish a more accurate history of what the trouble was and how it started. The process of gathering a more complete history had its own calming effect. It also helped me understand the patients' psychological dynamics in a more precise way. As their strengths and weaknesses emerged more clearly, I could appreciate the interaction between the normal and gifted parts of their personalities and begin to differentiate their emotional responses to their environment from their responses to their own inner experience of being gifted. Patients felt they could work through their interpersonal conflicts with parents, peers, and school more easily if they could get a better grip on what they felt were deeper emotional problems with giftedness itself. 
The Beginning Phase of Psychotherapy

As they settled into psychotherapy, patients cautiously revealed how conflicted they felt about being given exceptional capacities and abilities. At times, they felt exhilarated about having clear advantages over their friends, but they also felt guilty and ashamed when they felt superior to them. They knew they should not feel this way; nevertheless, they sheepishly acknowledged that at times they did.

When they told me about their secret hopes for how their giftedness might develop, how their visions included a feeling that a special destiny awaited them, they also wanted to describe how their passionate dreams were invaded by worries that they might be slipping into a fantasy world of self-aggrandizement.

In this early stage of therapy, I needed to be a psychologically informed mentor, coach, and advisor, as well as a therapist. As a therapist, I helped each patient explore and elaborate his or her visions for giftedness as well as his or her emotional responses to them. These patients felt capable of making important breakthroughs and major contributions. But they also were plagued by fears that they might become arrogant and self-centered in the process.

As a mentor, coach, and advisor, I encouraged them to explore how they could pursue their dreams in the real world. When we examined their past accomplishments objectively and reviewed what their teachers and other coaches had said about their true potential, my patients tentatively began to believe that they were not imposters or idle dreamers and began to see, along with everyone who believed in them, that if they could sustain their passion and were prepared to make sacrifices and work hard their dreams could come true.

Some of their visions were well-formed and others were embryonic. To help each patient clarify and organize his or her thinking about his or her visions, I expressed my own opinions, asked questions, gave advice, and commented on what might be too challenging or not challenging enough. At times, I played the devil's advocate and could be gently provocative.

Our interactions could be serious and philosophical or focused on practical strategies for material success. We could also be playful when we considered how the morbid and grotesque might be mixed with the beautiful and tasteful. No ideas were considered too outlandish. 
This wide-open style minimized the off-putting formality of a more traditional psychotherapeutic approach.

A certain amount of therapeutic transparency was also useful. It seemed to help my patients determine whether I was funny enough, stable enough, intelligent enough, and, especially, interesting enough for them to continue in the therapy. As they started to believe in the therapeutic process and me, they could acknowledge how it and I were making an important difference in their lives. Their first psychological breakthrough occurred when they realized that their underachievement and self-destructive behavior were not signs of gifted endowment gone badly or a poor environmental fit but were unconscious ways of disavowing their exceptional potential.

However, this increasing sense of trust also created another conflict and potential roadblock to further therapeutic work. By now they were convinced that I really did "get" giftedness. They could even acknowledge that I understood aspects of the gifted experience that they themselves had not. Admitting that my suggestions, observations, clarifications, and interpretations were very helpful meant accepting that I knew more about human psychology than they did. Becoming aware of this meant that further therapeutic work could yield deeper insights, but it also made each patient feel somewhat inadequate. "If I'm so gifted, how come I couldn't figure this out myself ?" was a frequently asked question. Fortunately their desires to learn more about their own gifted psychology, their desire to master underachievement and self-destructive behavior, and their desire to use their full potential overcame their competitive feelings. Resolving this conflict allowed the therapy to move to the next level, one in which they could explore their core conflicts about being exceptionally and profoundly gifted.

\section{Central Anxieties and Conflicts Explored in the Middle Phase of Psychotherapy}

As each patient wanted to learn more about the psychology of his or her inner experience of giftedness, I began to introduce my patients to some of the basic concepts of psychodynamic psychology. These concepts were integrated into the flow of the sessions and provided a foundation for understanding their behavior and symptoms while they tried to change them. 
The first step was to explain the universal nature of psychological conflict and that psychological conflict and anxiety were not signs of mental weakness. Next, I explained how intrapsychic conflicts originate, that anxiety is a symptom of unresolved psychological conflict, and how conflict and anxiety are mediated by a range of psychological defense mechanisms: Immature, maladaptive defense mechanisms attempt to deny and eliminate anxiety and conflict and often cause underachievement, self-destructive behavior, and psychological symptoms; mature, adaptive defense mechanisms, on the other hand, help conflicts become challenges that encourage the full use of gifted potential for consistent, creative, and positive accomplishments (Vaillant, 1971, 2000).

Autonomy Versus Dependency. As young children, all of my patients felt that their unusual endowment was all that was necessary for continued success. Rather than ask for help when they got stuck, they floundered, procrastinated, or withdrew, insisting that their motivation had mysteriously dried up. They believed that depending on others risked contaminating the "purity" of their giftedness or, worse, that they were not gifted after all. Rather than admit that they were overwhelmed and needed help, they rationalized their declining level of accomplishment by insisting that they had developed incurable neurological illnesses or hopeless esoteric learning disabilities that could not be treated.

As we carefully reviewed their histories, the patients began to realize that their gifted development had not occurred in some uncomplicated, autonomous way. Instead, it was the result of a successful combination of their curiosity and drive for mastery as well as the dedication and devotion of others, special resources, and formative experiences. Their parents had located stimulating extracurricular activities, found appropriate teachers, acquired special equipment, and, in many cases, excused them from household chores. Teachers had provided expertise, inspiration, and a solid work ethic and were role models for professionalism. Slowly, each patient began to see that his or her belief in the capacity to function with complete autonomy was a myth. Self-absorption-a fascination with their own curiosity, the power of their internal drives, their strange sensitivities and sensibilities, and the amazement at their own precocious accomplishments—-had apparently blinded the patients to their obvious dependency on others. 
Gradually dropping their façade of independence and invincibility, the patients began to make more use of the therapeutic relationship and therapeutic process. They did not have to face conflict and anxiety alone. They began to understand that avoidance, denial, and other attempts to completely eliminate anxiety and conflict were far more damaging to their gifted potential than the small compromises in autonomy that came from asking for help. Psychotherapy became a more collaborative process and one that began to help them establish more effective methods of conflict resolution.

Guilt. Few patients ever introduced themselves to me as gifted. It was only in the middle stage of psychotherapy that some permitted me to refer to them as gifted. As children, each of my patients disliked being called gifted. They thought gifted was a code word for odd, troubled, or just plain different. They sensed that they were a challenge for their parents and teachers and came to quietly believe that they needed to be managed in some special way. Secretly, they liked to think of themselves as better than others, but having an unfair advantage because of their precocious abilities also made them feel ashamed, embarrassed, and guilty. Although they frequently used their exceptional sensitivities and sensibilities in creative and spectacular ways, they felt their ability to do so was "weird" and "creepy." None of my patients could accept their giftedness as a simple fact of life, and none liked feeling different from their friends.

In science classes, they learned that the earth had only a limited supply of physical resources. Although they never discussed this with anyone, they thought that this same limitation must also apply to the world's supply of "mental resources." Because they had been "given" more endowment, they felt others had been robbed of their fair share. Firmly convinced they had mistakenly been given traits and abilities that belonged to others, they quietly figured out ways to equalize the difference.

Gifted polymaths felt they should have been allowed to succeed in only one domain. As children, they were generally admired and popular and rarely subjected to intense jealousy or malicious envy. Yet, they still believed that even in noncompetitive situations their success meant someone else's failure. Well into adulthood, they held onto an irrational belief that when they succeeded in using their powerful 
intellect or artistic sensibility, it humiliated others: All accomplishments took place in a sort of gigantic zero sum game in which their "win" was someone else's loss.

The process of reality testing these beliefs was a slow one. By examining the effects of their current success, the patients saw little evidence for jealousy. Friends were grateful for, not humiliated by, their help. Generosity was repaid with admiration. Slowly, worries about the destructive power of their giftedness receded.

Another insight emerged during this phase of the treatment. The patients began to realize that their larger-than-life successes did not mean that they lived outside the boundaries of human nature or were exempt from its laws. Although their intrapsychic conflicts were about their unusual strengths, the normal parameters of conflict resolution still applied to them. Just like their friends, they had to find mature ways to handle conflict and anxiety if they wanted to succeed in the real world.

By the middle phase of psychotherapy, the therapeutic relationship with me had become part of the reality-testing process. Rather than damaging the purity of giftedness, collaborating with me had released more of its potential. Psychotherapy obviously was not a zero-sum game. When patients understood how psychotherapy worked, I was pleased, not jealous, that they had succeeded in my domain, and I supported their insightful clarifications and connections. When I offered my insights, they could observe their competitive impulses rather than act them out by rejecting what I had given them. This deeper collaboration, one in which we both felt pleased and successful, not inadequate or defeated, was preparation for the next stage of therapy.

\section{The Late Phase of Psychotherapy: Extracognitive Elements}

In the final phase of psychotherapy, the content and process focused on what my patients felt were the deepest, but most troublesome part of their giftedness: the nature of and the conflicts and anxieties within the extracognitive part of their gifted endowment. For many of my patients, it was the first time they had ever attempted to examine this area of their inner experience of giftedness or share it with someone else.

The Extracognitive Elements of Gifted Endowment. Shavinina and Seeratan (2004) and Marton, Fensham, and Chaiklin (1994) discussed 
reports of Nobel Prize winning scientists who used what they described as extracognition, or intuitive abilities and aesthetic sensibilities, in their work. These scientists welcomed these qualities with no apparent conflict or anxiety. For my gifted patients, however, the presence and use of these extracognitive aspects of their giftedness were the source of confusing and disturbing conflicts and anxieties. As youngsters, each of my patients was aware of a part of their giftedness that went beyond the logic of their intelligence. Not knowing what to call it, they described it as an uncanny ability to "read" people and to "connect" and "see" unusual relationships between colors, sounds, and objects. They felt these abilities allowed them to almost instantly see solutions to complex personal and intellectual problems, to quickly sense the meaning and theory behind a new piece of music, or see unusual possibilities for artistic interpretation and performance. Privately, they were amazed by these abilities, but, well into adulthood, they were bothered by their inability to understand what these qualities were and how they worked. This part of their gifted endowment seemed to operate according to a mysterious set of rules in some murky world of the unconscious.

Intellect was the most stable part of their gifted endowment because it worked logically and seemed very reliable. Curiosity, inspiration, imagination, clairvoyance, and various special physical and aesthetic sensitivities and sensibilities were more elusive. When these qualities were active, they seemed to enhance and facilitate intellect in the process of discovery and mastery. Sometimes, these extracognitive qualities and abilities could actually bypass intellect by providing bold, clear, and immediate insights into where to begin an exploration or how to bring it to an elegant conclusion.

When these extracognitive qualities were absent, my patients thought that the essence of their giftedness had disappeared. At these times, they felt "only very smart" or "very capable," but also strangely deflated, vacant, or empty. The patients knew that there was some sort of reciprocal relationship between their intellect and the extracognitive parts of their mind, but they could not quite figure out how or what it was. When their intellect and extracognition operated in synergy, the results could be remarkable and the experience transforming-almost spiritual. Some patients described this as "like being in a profound twilight zone." They were convinced that the real magic of giftedness was located somewhere in this extracognitive domain, but 
they often became anxious when they thought about it too much and were embarrassed when they tried to tell anyone else about it. Some of my patients knew that successful scientists had used their intuition and imagination to achieve major breakthroughs (e.g., Isaacson, 2007; Miller, 1992). Other patients were aware that Picasso's novel artistic conceptions and Stravinsky's avant-garde music seemed outrageous at first but later became foundations for future artists and musicians. However, when my patients imagined that their minds might actually be of this same caliber, they became frightened and negated the possibility. Once they knew they could really trust me, each patient was eager to describe his or her muddled intuitive world.

Extracognition in the Process of Discovery and Exploration. Curiosity was always present, as each of my patients had strong affinities for particular artistic and intellectual problems-the more complex, the better. While investigating their private worlds, they often felt like a character in the story, King Solomon's Mines (Haggard, 1938), except, in their version, the treasures were a kaleidoscope of beautiful sensations, perceptions, and observations. At first, each avenue of discovery had a separate but equal valence, but soon lines of connection between them became clear, patterns developed, and rudimentary concepts emerged. Inspired, their imagination elaborated visions for what all of this could become. Clairvoyance, their special ability to see beyond the ordinary, gave them an almost kinesthetic feel for the most productive paths to follow. As part of this process, they began to imagine who they might become should their discoveries evolve into major contributions. However, as we delved further into their methods of discovery and exploration, each patient revealed a set of conflicts and anxieties that often accompanied the process.

\section{Conflicts and Anxieties Within the Extracognitive Domain of Giftedness.} In the beginning, weaving together strands of meaning into beautiful patterns and then unraveling them for equally aesthetic alternatives was simply great fun. Many of my patients described the experience as akin to "living in a continuous mind buzz" or being on an endless "natural high." At times, they were able to organize many elegant and potentially useful possibilities. In this more controlled state, the process was exciting and gratifying. 
Trouble started, however, when they became so exhilarated that they felt intellectually and emotionally flooded. The sense of endless possibilities and the feeling of grandiose personal power broke through normal logical and emotional boundaries, making meaningful choices seem impossible. Clarity dissolved into a frightening state of overstimulation. Intuition seemed like wishful thinking. Some patients felt they were headed for a place described in one of their favorite childhood books, Where the Wild Things Are (Sendak, 1984). More trouble came when they overheard themselves being described as "scary" or "frighteningly smart." Uncomfortable with those descriptions, they tried to disavow their "weird" brilliance, but the internal forces of gifted endowment kept pressing outward for satisfaction.

As they had grown older, they had minimized the meaning of the intuitive part of giftedness and described it as a knack for solving problems quickly. Flashes of insight were used to find answers in the fastest way with the least effort. Extracognition became about speed, not depth.

There seemed to be little conflict with breaking time barriers, cutting corners, and getting more free time. The mind buzz now came from working outside all conventional boundaries and feeling exempt from ordinary restrictions and limitations. They began to play up a geeky identity, taking provocative delight in speed and rebellion for its own sake. Accomplishments became sporadic and less meaningful. This expression of the extracognitive part of giftedness became somewhat addictive, and speed and rebellion took on a life of its own. The fascination of getting to the bottom of things, stretching conventional artistic or scientific boundaries in creative ways, had all but disappeared. This new turbo-charged form of giftedness helped them sidestep conflicts and anxieties about the profound or the philosophical.

As my patients became older adolescents and young adults, the intellectual and artistic challenges became progressively more complex. Finding novel solutions took longer. Exceptional accomplishments now required more thought about the interplay between the extracognitive and intellectual. This change meant that the process of discovery and exploration had to become more incremental and less instantaneous. Discoveries were more likely to go from one plateau to the next. Answers and results sometimes came in days or weeks rather than minutes or hours and the successful use of gifted endowment 
required more attention to the useful and functional. Rather than cut corners to finish first, they needed to embrace the slow back-and-forth process of integrating their intellectual abilities with their extracognitive ones. Satisfaction would then come from careful deep exploration instead of winning competitions.

Different kinds of strange and unwieldy problems existed here, notwithstanding. When the extracognitive elements all worked in synergy, work proceeded smoothly, but the need for so little effort was unnerving. What happened when these elements conflicted with one another? Focusing on the proper balance between intuition and intellect could be confusing. How far should one go with intuitive insights before testing them with intellectual rigor? One would not want to continue along a path that would ultimately be a waste of time. Nor would one want to prematurely choke off imaginative ideas that could lead to deep insights just because they seemed superficially outlandish.

This slower process of allowing extracognition and intellect to work independently as well as be guided by one another could cause immobilizing anxiety and obsessive self-doubt. It was at these times when my patients could feel wonderfully inspired but simultaneously convinced that they were too slow or dull to be really gifted.

A new challenge for giftedness had emerged as they had grown older. How could they be passionate and playful, yet productive enough so that they could regulate the speed and immediacy of their extracognition with the care and thoughtfulness of intellect? Dealing with conflicts about friends, parents, school, or work were simple compared to this.

\section{How Did the Therapeutic Process Help Resolve Conflicts About the} Extracognitive Elements of Giftedness? In order for advice, guidance, observations, clarifications, and interpretations to be effective, they need to be accurate and timed properly. Analytic skills are certainly necessary but not sufficient in this process. Intuition also plays a role. In this later stage of psychotherapy, my patients became more comfortable using their intuitive skills along with their analytical ones. Often an intuitive leap by either one of us could stimulate powerful emotional responses and deeper insights. This here-and-now validation of the intuitive parts of the therapeutic process encouraged my patients to value their own extracognitive abilities so that they could take their rightful place alongside their intellectual ones. 
As my patients came to understand and experience the many-layered meanings of their deeper conflicts and associated emotions, the primitive psychological defenses of avoidance, denial, and acting out through underachievement and self-destructive behavior could be abandoned in favor of more mature methods of conflict resolution. Gifted potential could now be used more productively with less conflict and anxiety.

\section{Summary}

Psychodynamic psychotherapy was used to treat underachievement, self-destructive behavior, and a variety of psychological symptoms in exceptionally and profoundly gifted adolescents and adults. Each patient's psychotherapy unfolded in a series of recognizable stages, and each stage addressed similar issues.

Crisis management required a directive approach, accurate symptom diagnosis, and suggestions for stress management. As each patient's crisis resolved, conveying an understanding of the inner experience of giftedness often prevented premature withdrawal from therapy.

A therapeutic alliance developed and treatment went beyond symptom relief. A more complete assessment process permitted the development of a psychodynamic formulation. This formulation invariably revealed that although conflicts with parents, peers, school, and work were always factors, the primary causes of underachievement, self-destructive behavior, and psychological symptoms in many of my patients were unresolved conflicts about their inner experience of giftedness. The formulation also helped focus and guide the therapy through the remaining stages.

In the second phase of therapy, the patients began to address their shame and embarrassment, as they clarified and elaborated a vision for their giftedness and attempted to find a setting for its expression. As the therapy unfolded, the most effective approach was a lively interactive one that combined psychologically informed mentoring, coaching, and advising with standard psychotherapy techniques.

The principles of psychodynamic psychology were integrated into the flow of the sessions in the third phase of psychotherapy. Understanding that the presence of anxiety and psychological conflict 
were not signs of mental weakness, attempts to completely eliminate anxiety and conflict would seriously restrict normal as well as gifted development. Psychological conflicts needed to be understood and anxieties needed to be experienced and expressed directly so that effective methods of resolving conflicts could be substituted for the less effective methods of underachievement and self-destructive behavior. This awareness helped prepare patients for this third phase of psychotherapy. Now each patient could discuss and examine several important central conflicts: the desire for autonomy vis-à-vis the need to depend on others, and feelings of pleasure and excitement when using one's special endowment vis-à-vis guilt at having been given too much.

In the fourth phase of psychotherapy, patients worked to resolve conflicts and anxieties about the true essence of their giftedness. They explored how the different elements of their extracognitive endowment conflicted with one another; how the extracognitive conflicted with the intellectual; and how the fun of quick solutions that broke conventional rules conflicted with the possibilities for profound exploration. This final phase of psychotherapy helped my patients use their analytic as well as their intuitive skills to recognize and resolve the complex conflicts of exceptional and profound giftedness.

\section{Conclusion}

Psychodynamic psychotherapy revealed that a group of unresolved core conflicts about the inner experience of giftedness were the primary causes of underachievement, self-destructive behavior, and serious psychological symptoms in a group of exceptionally and profoundly gifted adolescents and adults. A lively, interactive combination of psychologically informed mentoring, coaching, advising, and more flexible psychotherapy techniques addressed guilty feelings about being given too much endowment, an insistence on autonomous functioning, confusion about integrating extracognitive abilities with the intellect, and using gifted endowment to explore the profound aspects of important problems instead of finding speedy solutions to them. More mature methods of conflict resolution evolved as did a highly effective collaboration: These methods integrated the analytic and 
intuitive and allowed the release and use of more gifted potential with less conflict and anxiety.

\section{References}

American Psychiatric Association. (1994). Diagnostic and statistical manual of mental disorders (4th ed.). Washington, DC: Author.

Colangelo, N., \& Assouline, S. G. (2000). Counseling gifted students. In K. A. Heller, F. J. Mönks, R. J. Sternberg, \& R. F. Subotnik (Eds.), International handbook of giftedness and talent (2nd ed., pp. 595-607). Amsterdam: Elsevier.

Colarusso, C. A. (1980). Psychoanalysis of a severe neurotic learning disturbance in a gifted adolescent boy. Bulletin of the Menninger Clinic, 44, 585-602.

Dahlberg, W. (1992). Brilliance: The childhood dilemma of unusual intellect. Roeper Review, 15, 7-10.

Grobman, J. (2006). Underachievement in exceptionally gifted adolescents and younger adults: A psychiatrist's view. Journal of Secondary Gifted Education, 17, 199-210.

Haggard, H. R. (1938). King Solomon's mines. New York: Longman's Green.

Isaacson, W. (2007). Einstein: His life and universe. New York: Simon and Schuster.

Jacobsen, M. (1999). Arousing the sleeping giant: Giftedness in psychotherapy. Roeper Review, 22, 36-42.

Kelly, K. (1970). A precocious child in analysis. Psychoanalytic Study of the Child, 25, 122-145.

Kerr, B. (2007). Science, spirit, and talent development. In S. Mendaglio \& J. S. Peterson (Eds.), Models of counseling gifted children, adolescents, and young adults (pp. 231-252). Waco, TX: Prufrock Press.

Lovecky, D. (1990). Warts and rainbows: Issues in psychotherapy of the gifted. Advanced Development Journal, 2, 107-125.

Marton, F., Fensham, P., \& Chaiklin, S. (1994). A Nobel's eye view of scientific intuition: Discussion with the Nobel prize-winners in physics, chemistry and medicine (1970-1986). International Journal of Science Education, 16, 457-473. 
Mendaglio, S., \& Peterson, J. S. (Eds.). (2007). Models of counseling gifted children, adolescents, and young adults. Waco, TX: Prufrock Press.

Miller, A. (1992). Scientific creativity: A comparative study of Henri Poincare and Albert Einstein. Creativity Research Journal, 5, 385-418.

Oremland, J. D. (1975). An unexpected result of the analysis of a talented musician. Psychoanalytic Study of the Child, 30, 375-404.

Perry, S., Cooper, A. M., \& Michels, R. (1987). The psychodynamic formulation: Its purpose, structure and clinical application. American Journal of Psychiatry, 144, 543-550.

Rocamora, M. (1992). Counseling issues with recognized and unrecognized gifted adults, with six case studies. Advanced Development, 4, 147-161.

Sendak, N. (1984). Where the wild things are. New York: Harper Collins.

Shavinina, L., \& Seeratan, K. (2004). Extracognitive phenomena in the intellectual functioning of gifted, creative and talented individuals. In L. Shavinina \& N. Ferrari (Eds.), Beyond knowledge: Extracognitive aspects of developing high ability (pp. 73-101). Mahwah, NJ: Lawrence Erlbaum.

Silverman, L. K. (Ed.). (2000). Counseling the gifted and talented. Denver, CO: Love.

Vaillant, G. E. (1971). Theoretical hierarchy of adaptive ego mechanisms. Archives of General Psychiatry, 24, 107-118.

Vaillant, G. E. (2000) Adaptive mental mechanisms: Their role in a positive psychology. American Psychologist, 55, 89-98.

\section{Author Note}

The author wishes to thank Madelon Sann, LCSW, for sharing her clinical insights and helpful editorial comments; Andrea D. Frazier for her help in preparing the manuscript for publication; Jennifer Robins and Roger Cohn, Assistant Director of the Northeast Millerton Library, and the staff of The New York Society Library for finding resources and materials. 